\title{
Nurses' educational needs in the oral health of inpatients at Yazd Province in Iran: a Delphi study
}

Seyed Hosein Tabatabaei ${ }^{1} \mathbb{D}$, Fatemeh Owlia ${ }^{2} \mathbb{D}$, Fatemeh Ayatollahi ${ }^{3} \mathbb{D}$, Fahimeh Rashidi Maybodi ${ }^{4} \mathbb{D}$, Hakimeh Ahadian ${ }^{2}$ (D) Fatemeh Azizian ${ }^{5}$ (D) and Khadijeh Nasiriani ${ }^{6^{*}}$ (I)

\begin{abstract}
Background: Oral hygiene is an integral part of general health of a person. Nurses qualified about oral care can play an important role in improving the quality of oral health in hospitalized patients. This study investigated the educational needs of nurses in the field of oral health of hospitalized patients.

Methods: The study used the modified Delphi method in three rounds. Fifty faculty members of the School of Dentistry and Nursing were selected via purposive sampling. The data collection tool was a demographic form and an open-ended questionnaire in the first round and a structured questionnaire in the next rounds. The analysis was performed using both content and descriptive analysis techniques.

Results: The top ten oral health education priorities for nurses were greater than $75 \%$ with a consensus level: oral anatomy and physiology, learning the signs and symptoms of common oral diseases, learning of oral medications and administration, learning the drugs that cause damage to the mouth and teeth, training in managing dental emergencies, patient education for tooth brushing and taking care of the mouth, especially in the elderly patient, providing oral and dental care, training for unconscious and fasting patients, undergoing chemotherapy and radiotherapy, and hospitalization in intensive care unit.
\end{abstract}

Conclusion: The findings of the study emphasized the need for interdisciplinary cooperation between nursing and dental professionals for the development of an oral health curriculum for nurses to promote and improve oral health and prevent dental diseases in hospitalized patients and the community.

Keywords: Oral hygiene, Oral health, Patient, Needs assessment, Nurse, In-patients

\footnotetext{
* Correspondence: nasiriani@gmail.com

${ }^{6}$ Department of Nursing, School of Nursing, Mother and Newborn Health Research Center, Nursing and midwifery Research Center, Shahid Sadoughi University of Medical Sciences, Yazd, Iran

Full list of author information is available at the end of the article
}

(C) The Author(s). 2020 Open Access This article is licensed under a Creative Commons Attribution 4.0 International License, which permits use, sharing, adaptation, distribution and reproduction in any medium or format, as long as you give appropriate credit to the original author(s) and the source, provide a link to the Creative Commons licence, and indicate if changes were made. The images or other third party material in this article are included in the article's Creative Commons licence, unless indicated otherwise in a credit line to the material. If material is not included in the article's Creative Commons licence and your intended use is not permitted by statutory regulation or exceeds the permitted use, you will need to obtain permission directly from the copyright holder. To view a copy of this licence, visit http://creativecommons.org/licenses/by/4.0/. The Creative Commons Public Domain Dedication waiver (http://creativecommons.org/publicdomain/zero/1.0/) applies to the data made available in this article, unless otherwise stated in a credit line to the data. 


\section{Background}

Oral hygiene is an integral part of general health that should be maintained throughout life, as the mouth is considered the mirror of the body and the gateway to health [1, 2]. Numerous studies have shown the poor condition of oral hygiene and inadequate access to oral care in hospitalized patients [3] and that oral health $(\mathrm{OH})$ deteriorates during hospitalization [4]. $\mathrm{OH}$ is neglected, especially in the elderly, partly because they need to care on many levels; as a result, less time is reserved for $\mathrm{OH}$ care [5]. Also, plaque and tongue coverage indices increase with hospital stay in the intensive care unit [6]. In the other words, hospitalization is associated with deterioration of $\mathrm{OH}$, particularly in intubated and elderly patients $[7,8]$.

The study by Carrilho Neto et al. (2011) showed most of the patients had poor oral hygiene, gingivitis, periodontal disease, and dental decay [9]. This has been due to the lack of promotion and control program in the $\mathrm{OH}$ care setting [10]. On the other hand, various studies have confirmed the effects of oral diseases, especially periodontal diseases, on some systemic diseases including cardiovascular disease [11], lung disease (including COPD) and pregnancy problems and complications, including low birth weight, premature birth, growth retardation, and preeclampsia [12]. Most of oral diseases can be prevented [13].

Nurses are one of the largest healthcare group [14] that play an important role in providing health care services and promoting health and disseminating preventive information $[13,15]$. Nurses may be important in detecting oral diseases and educating patients, especially in countries with limited human resources and a shortage of dental professionals [16, 17]; Yao et al. (2019) \& Philip et al. (2019) showed the nurses' knowledge was poor and inadequate in $\mathrm{OH}$ care $[1,15]$. Also, oral care is insufficient in hospitalized patients, especially high-risk patients. This could be caused by lack of training $[18,19]$.

In general, studies have shown that nurses need to improve their knowledge about $\mathrm{OH}[13,20]$. Therefore, more attention should be paid to the issue of $\mathrm{OH}$ in nursing curriculum $[13,19,20]$. Considering the importance of $\mathrm{OH}$ for the promotion and maintenance of public health and welfare $[14,20]$, it is so necessary to maintain $\mathrm{OH}$ in people hospitalized to improve wellbeing outcomes and quality of life [21]. Besides, the negative consequences of poor $\mathrm{OH}$ in hospitalized patients are significant, specially in patients with an artificial airway [14]. Nurses, as primary care providers, need sufficient knowledge, positive attitude, and acceptable performance to be able to provide effective $\mathrm{OH}$ care [21]. This issue should be considered in nurses' training programs. Nonetheless, studies show an obvious lack in nursing curriculum $[14,20]$. In a national survey of 1000 US nursing education programs, more than half of schools reported that there was a shortage of curriculum content, and lack of faculty time, interest, and expertise in health education, including $\mathrm{OH}$ [14]. Likewise, Jablonski (2012) demonstrated the content devoted to oral hygiene in nursing textbooks averaged $0.6 \%$ [22]. Based on the above-mentioned issues, this study was designed to investigate the educational needs of nurses about the $\mathrm{OH}$ of the hospitalized patients.

\section{Methods}

This study was performed using the modified Delphi method over three rounds. The Delphi method is a forecasting process framework based on the results of multiple rounds of questionnaires sent to a panel of experts that seeks to reach a correct response through consensus on a particular topic $[23,24]$. The panelist requires several characteristics such as: knowledge and experience in the subject, willingness and enough time to participate. The panelists of this study were faculty members and instructors of dentistry school and nursing school working at Shahid Sadoughi University of Medical Sciences, Yazd Province, Iran. The panelists were selected by purposive sampling. Participating nurses had at least 2 years of clinical work experience in the hospital and dentists also had work experience in the field of $\mathrm{OH}$ of hospitalized patients. The number of participants in Delphi's research is usually less than 50 and mostly 15 to 20 [25]. In this study, considering that two groups of nursing and dentistry participated and with the probability of attrition of panelists in the rounds, 25 samples were considered in each group and a total of 50 people participated.

Data collection tool was a questionnaire. In each round, a summary of the results of the previous round was evaluated by the panelists. In the first round, an unstructured questionnaire was sent to the participants by e-mail, and they were requested to complete the demographic information including age, gender, level of education, work experience and an open-ended question: "In your opinion, what are the educational priorities of nurses in the field of improving the $\mathrm{OH}$ of hospitalized patients?" Participants were free to express any ideas and opinions about the educational needs of $\mathrm{OH}$ nurses and write a list of topics of interest. The items obtained from the first round were analyzed. Also, at the end of this round, the literature was reviewed for finding related issue, the categories extracted from the first round as a structured questionnaire to be used as tools for the second round. In the second round, the participants were asked to answer the items on a Likert scale (not important, important, and very important). Therefore, about the importance of ranking, only items were accepted that scored above $75 \%$ and were ranked as 
important and very important. In the third round, all items that were accepted in the second round were sent to the experts to express their agreement or disagreement with the items. The items were accepted that obtained an agreement score above or equal to $75 \%$. In most Delphi studies, the criterion for consensus was percentage of agreement by $75 \%$ [26]. The remained approved items were declared as $\mathrm{OH}$ educational needs required by nurses.

The analysis was performed using both quantitative and qualitative methods. Data analysis was performed in the first round of this study with conventional content analysis approach [27]. Qualitative content analysis is one of the qualitative methods currently available for analyzing data and interpreting its meaning and an autonomous method that can be used at varying levels of abstraction and interpretation [28]. In conventional content analysis, coding categories are derived directly from the text data. In this study, conventional content analysis was done based on the Lundman \& Graneheim method in which codes, category, and themes are compared for similarity and differences [29]. IBM SPSS Statistics 16 was used to analyze the absolute and relative frequency in the second and third rounds.

This study was the second phase of a project of the designing, implementation and evaluation of a specific nursing educational program in $\mathrm{OH}$ of hospitalized patients, which was approved by the Committee of Ethics in Human Research at Shahid Sadoughi University of Medical Sciences in Yazd. In this study, an informed consent was obtained from the participants. Eligible participants were informed about the aim of the study, the method, and confidentiality of their responses by e-mail.

\section{Results}

In this study, 25 nurses and 25 dentists participated in the first round. (The demographic characteristics are presented in Table 1). In the second round, 2 dental

Table 1 Demographic characteristics of the participants

\begin{tabular}{ll}
\hline Variables & Data value \\
\hline Gender & $37(74)$ \\
Female & $13(26)$ \\
Male & \\
Field of Study & $25(50)$ \\
$\quad$ Nursing & $25(50)$ \\
Dentistry & \\
Degree of Education & $17(34)$ \\
M.Sc. degree & $33(66)$ \\
PhD or professional doctorate degree & $34.9 \pm 7.36$ \\
Age (yr) & $7.94 \pm 6.75$ \\
work experience (yr)
\end{tabular}

Values are given as $\mathrm{n}(\%)$ or range (mean) faculty members did not return the questionnaire. Also, in the third round, 1 nursing faculty member did not return the questionnaire.

In the first round, the participants were asked to write the educational needs of nurses in the $\mathrm{OH}$ of inpatients. The dental participants further stated aspects of $\mathrm{OH}$ theory such as oral anatomy and physiology, familiarity with the signs and symptoms of common oral diseases, etc. However, the nurses emphasized more the clinical aspects of oral care such as providing oral for NPO and the elderly patient, etc. The results of the open questionnaires were analyzed by content analysis, which resulted in the extraction of 300 initial codes which were placed on the first 27 categories (Table 2).

After extracting the presented categories from the interview, the literature was reviewed. Then, the categories were revised and 20 items were sent for the second round in a structured questionnaire. In the second round, the importance of the items was examined. It was considered an accepted item if the sum of the relative frequency level of importance (Very Important and Important) was above $75 \%$ and the rest were removed. The removed 6 items were: introducing drugs that affect oral disorders (methods of treating oral problems, such as in radiotherapy), how to use dental consultation and refer to a dentist, teaching children periodic oral examinations, brushing training for special patients, and teeth fluoride varnish training. In the third round, the items approved in the second round were sent to experts in the agreed/disagreed format to prioritize nurses' educational needs in the $\mathrm{OH}$ of in-patients. Items for which the panelists reached an agreement above $75 \%$ were accepted for the last round and the rest were eliminated. So, 5 items on "the relationship between diseases such as respiratory diseases, diabetes, heart disease, etc. and $\mathrm{OH}$ problem", "problems with wearing dentures and how to remove them", "familiarity with interventions for controlling halitosis (bad breath)", "providing oral and dental care for patients under oropharyngeal candidiasis", and "providing oral and dental care for patients with maxillofacial trauma” were removed. (Table 3).

Finally, the 10 approved items were confirmed as educational priorities for $\mathrm{OH}$ in nursing (Table 4).

\section{Discussion}

In this study, the educational needs of nurses in oral and dental health of hospitalized patients were identified. According to some studies, nurses are not satisfied with the health of the mouth and there is a need for training [30, 31]. Therefore, there is a need for training and education.

According to the findings, there were ten educational priorities of the nurses in the field of $\mathrm{OH}$ for hospitalized patients. Of course, each has been a topic and the 
Table 2 Primary categories extracted in the qualitative content analysis of the first round

\begin{tabular}{|c|c|c|}
\hline$\neq$ & Primary Categories & Number of codes \\
\hline 1 & Oral Anatomy and physiology & 24 \\
\hline 2 & Familiarity with the signs and symptoms of common oral diseases & 20 \\
\hline 3 & $\begin{array}{l}\text { The relationship between diseases such as respiratory diseases, } \\
\text { diabetes and oral health problem }\end{array}$ & 10 \\
\hline 4 & $\begin{array}{l}\text { Teaching dental emergencies (Sudden toothache, cheek swelling } \\
\text { due to toothache.) }\end{array}$ & 18 \\
\hline 5 & $\begin{array}{l}\text { Introducing drugs that affect oral disorders (methods of treating } \\
\text { oral problems, such as in radiotherapy) }\end{array}$ & 18 \\
\hline 6 & Education of periodic examination of the mouth & 10 \\
\hline 7 & Problems with wearing dentures and how to remove them & 8 \\
\hline 8 & $\begin{array}{l}\text { Familiarity with prescribed medications for oral problems and oral } \\
\text { medication administration }\end{array}$ & 25 \\
\hline 9 & Introducing drugs that cause damage to the mouth and teeth & 36 \\
\hline 10 & Familiarity with interventions controlling bad breath (halitosis) & 5 \\
\hline 11 & How to use dental consultation and refer to a dentist & 11 \\
\hline 12 & Teaching children periodic oral examinations & 5 \\
\hline 13 & Mouthwash training & 12 \\
\hline 14 & Brushing training for special patients & 30 \\
\hline 15 & $\begin{array}{l}\text { Patient education for tooth brushing and taking care of the mouth, } \\
\text { especially in the elderly patient }\end{array}$ & 40 \\
\hline 16 & Teeth fluoride varnish training & 5 \\
\hline 17 & Providing oral and dental care for unconscious patients & 30 \\
\hline 18 & Providing oral and dental care for NPO patients & 32 \\
\hline 19 & $\begin{array}{l}\text { Providing oral and dental care for patients undergoing } \\
\text { chemotherapy and radiotherapy }\end{array}$ & 22 \\
\hline 20 & $\begin{array}{l}\text { Providing oral and dental care for patients under oropharyngeal } \\
\text { candidiasis }\end{array}$ & 8 \\
\hline 21 & $\begin{array}{l}\text { Providing oral and dental care for patients with maxillofacial } \\
\text { trauma }\end{array}$ & 13 \\
\hline 22 & $\begin{array}{l}\text { Providing oral and dental care for patients admitted to critical } \\
\text { care unit }\end{array}$ & 41 \\
\hline 23 & Education of proper nutrition & 10 \\
\hline 24 & Electric toothbrush & 3 \\
\hline 25 & Flossing & 6 \\
\hline 26 & Community health education and oral and dental care & 5 \\
\hline 27 & Providing oral and dental care for pregnant mothers & 2 \\
\hline
\end{tabular}

educational content must be developed for each of them.

Based on the findings, nurses who want to provide oral care for their patients in hospital must know the oral anatomy and physiology and the signs and symptoms of common oral diseases. They should have enough information about the medications that are prescribed to fight oral and dental diseases or about the medicines which can cause dry mouth (xerostomia) and increase the risk of tooth decay and drug administration route. Nurses need to learn what to do when a patient has tooth pain or swollen gums due to toothache.
Based on important findings of the study, that nurses need to learn about delivery of oral care to hospitalized patients is that the elderly are more often hospitalized and with longer hospital stays compared to other age groups; so, nurses must learn how to brush their teeth and take care of the mouth, especially in the elderly patient. Haresaku et al. (2018) showed almost half the nurses performed $\mathrm{OH}$ check-ups for elderly patients [32].

Another important finding is that nurses need to learn is concerned with delivery of oral care to hospitalized patients. It was emphasized that nurses should be able to provide $\mathrm{OH}$ care in this particular group of patients, 
Table 3 Results of the Second \& Third Round Delphi

\begin{tabular}{|c|c|c|c|c|c|c|}
\hline \multirow[t]{2}{*}{$\neq$} & \multirow{2}{*}{$\begin{array}{l}\text { Item of educational needs of nurses } \\
\text { in oral care of hospitalized patients }\end{array}$} & \multicolumn{3}{|l|}{ Important } & \multicolumn{2}{|c|}{ Consensus } \\
\hline & & $\begin{array}{l}\text { Very important } \\
\mathrm{n}(\%)\end{array}$ & $\begin{array}{l}\text { Important } \\
\mathrm{n}(\%)\end{array}$ & $\begin{array}{l}\text { Not important } \\
\mathrm{n}(\%)\end{array}$ & $\begin{array}{l}\text { Agree } \\
\mathrm{n}(\%)\end{array}$ & $\begin{array}{l}\text { Disagree } \\
\mathrm{n}(\%)\end{array}$ \\
\hline 1 & Oral Anatomy and physiology & $15(30 \%)$ & $32(64 \%)$ & $1(2 \%)$ & $41(87 \%)$ & $6(13 \%)$ \\
\hline 2 & Learning the signs and symptoms of common oral diseases & $14(29 \%)$ & $29(60.5 \%)$ & $5(10.5 \%)$ & $42(89 \%)$ & $5(11 \%)$ \\
\hline 3 & $\begin{array}{l}\text { The relationship between diseases such as respiratory } \\
\text { diseases, diabetes, heart disease, etc. and oral health } \\
\text { problem }\end{array}$ & $11(23 \%)$ & $31(64.5 \%)$ & $6(12.5 \%)$ & $8(17 \%)$ & $39(83 \%)$ \\
\hline 4 & $\begin{array}{l}\text { Training in managing dental emergencies (Sudden } \\
\text { toothache, cheek swelling due to toothache, etc.). }\end{array}$ & $6(12.5 \%)$ & $27(56.25 \%)$ & $15(30.25 \%)$ & $36(77 \%)$ & $11(23 \%)$ \\
\hline 5 & $\begin{array}{l}\text { Learning the drugs that affect oral disorders (methods of } \\
\text { treating oral problems, such as in radiotherapy) }\end{array}$ & $5(10.5 \%)$ & $12(25 \%)$ & $31(64.5 \%)$ & & \\
\hline 6 & Problems with wearing dentures and how to remove them & $10(21 \%)$ & $33(68.5 \%)$ & $5(10.5 \%)$ & $11(23 \%)$ & $36(77 \%)$ \\
\hline 7 & $\begin{array}{l}\text { Leaning the oral medications and oral medication } \\
\text { administration }\end{array}$ & $7(15 \%)$ & $34(75 \%)$ & $7(15 \%)$ & $39(83 \%)$ & $8(17 \%)$ \\
\hline 8 & Learning drugs that cause damage to the mouth and teeth & $8(17 \%)$ & $38(79 \%)$ & $2(4 \%)$ & $36(78 \%)$ & $11(22 \%)$ \\
\hline 9 & $\begin{array}{l}\text { Familiarity with interventions for controlling halitosis } \\
\text { (bad breath) }\end{array}$ & $8(17 \%)$ & $33(68.5 \%)$ & $7(14.5 \%)$ & $5(11 \%)$ & $42(89 \%)$ \\
\hline 10 & How to use dental consultation and refer to a dentist & $15(31.25 \%)$ & $11(23 \%)$ & $22(45.75 \%)$ & & \\
\hline 11 & Teaching children periodic oral examinations & $12(25 \%)$ & $10(21 \%)$ & $26(54 \%)$ & & \\
\hline 12 & Brushing training for special patients & $2(4 \%)$ & $18(37.5 \%)$ & $28(58.5 \%)$ & & \\
\hline 13 & $\begin{array}{l}\text { Patient education for tooth brushing and taking care of the } \\
\text { mouth, especially in the elderly patient }\end{array}$ & $18(37.5 \%)$ & $29(60.5 \%)$ & $1(2 \%)$ & $98(96 \%)$ & $1(2 \%)$ \\
\hline 14 & Teeth fluoride varnish training & $10(21 \%)$ & $5(10.5 \%)$ & $33(68.5 \%)$ & & \\
\hline 15 & Providing oral and dental care for unconscious patients & $36(75 \%)$ & $8(17 \%)$ & $4(8 \%)$ & $38(81 \%)$ & $9(19 \%)$ \\
\hline 16 & Providing oral and dental care for NPO patients & $34(70.5 \%)$ & $8(17 \%)$ & $6(12.5 \%)$ & $40(85 \%)$ & $7(15 \%)$ \\
\hline 17 & $\begin{array}{l}\text { Providing oral and dental care for patients undergoing } \\
\text { chemotherapy and radiotherapy }\end{array}$ & $41(85.5 \%)$ & $5(10.5 \%)$ & $2(4 \%)$ & $40(85 \%)$ & $7(15 \%)$ \\
\hline 18 & $\begin{array}{l}\text { Providing oral and dental care for patients under } \\
\text { oropharyngeal candidiasis }\end{array}$ & $38(79 \%)$ & $9(19 \%)$ & $1(2 \%)$ & $11(22 \%)$ & $36(78 \%)$ \\
\hline 19 & $\begin{array}{l}\text { Providing oral and dental care for patients with maxillofacial } \\
\text { trauma }\end{array}$ & $37(77 \%)$ & $10(21 \%)$ & $1(2 \%)$ & 7 (15\%) & $40(85 \%)$ \\
\hline 20 & $\begin{array}{l}\text { Providing oral and dental care for patients admitted to } \\
\text { critical care unit }\end{array}$ & 41 (85.5\%) & $6(12.5 \%)$ & $1(2 \%)$ & 98 (96\%) & $1(2 \%)$ \\
\hline
\end{tabular}

because they form a greater number of patients requiring hospitalization. These groups of patients include NPO and unconscious, admitted to critical care unit and undergoing chemotherapy and radiotherapy, critically ill patients with an artificial airway. Lee et al. (2019) indicated most participants considered that there is a need for evidence-based protocol for oral care for hospitalized patients, and nurses employed in the critical care unit are much more responsible in this regard compared to nurses working in the public ward [33].

Review of the related literature showed insufficient research to determine the educational requirements of $\mathrm{OH}$ for nurses, especially hospitalized patients. Moreover, the studies have been conducted about basic $\mathrm{OH}$. Rwakatema et al.(2015) declared nursing students had insufficient knowledge about basic oral hygiene [34]. However, studies showed positive impact of educational programs in $\mathrm{OH}$. Khanbodaghi et al. (2019) suggested the inter-professional education program in oral hygiene issues that can help ongoing dental surveillance [35].

On the basis of findings, the nurse requires more attention to assess the status of $\mathrm{OH}$ and offer the related care. In particular, mouth/oral care should be done for elderly, high-risk patients, and in hospitalized patients in Intensive Care Unit. In this regard, interdisciplinary cooperation between nurses and dentists must be enhanced to develop an $\mathrm{OH}$ care curriculum. Then, nurses should be educated about in-patients' oral care needs. In the future, wellqualified nursing workers can promote $\mathrm{OH}$ and prevent dental disease in hospitalized patients.

One of the limitations of the present study was the lack of participation of nursing and dental specialists 
Table 4 Oral health nursing educational needs in hospitalized patients

\begin{tabular}{|c|c|}
\hline$\neq$ & Oral health education priorities for nurses \\
\hline 1 & Oral Anatomy and physiology \\
\hline 2 & Learning the signs and symptoms of common oral diseases \\
\hline 3 & Learning of oral medications and administration \\
\hline 4 & Learning the drugs that cause damage to the mouth and teeth \\
\hline 5 & Training in managing dental emergencies \\
\hline 6 & $\begin{array}{l}\text { Patient education for tooth brushing and taking care of the } \\
\text { mouth, especially in the elderly patient }\end{array}$ \\
\hline 7 & Providing oral and dental care training for unconscious patients \\
\hline 8 & Providing oral and dental care training for NPO patients \\
\hline 9 & $\begin{array}{l}\text { Providing oral and dental care for patients undergoing } \\
\text { chemotherapy and radiotherapy }\end{array}$ \\
\hline 10 & $\begin{array}{l}\text { Providing oral and dental care for patients admitted to critical } \\
\text { care unit }\end{array}$ \\
\hline
\end{tabular}

from other universities and throughout the country. It is suggested that this shortcoming be considered in future studies.

\section{Conclusion}

In this study, ten topics were noted as the most important educational needs of nurses in the field of $\mathrm{OH}$ care. The educational needs assessment of nurses about $\mathrm{OH}$ of in-patients can lead to the designing, implementation and evaluation of the special nursing $\mathrm{OH}$ curriculum for training of undergraduate and graduate courses and nurses retraining.

\section{Supplementary Information}

The online version contains supplementary material available at https://doi. org/10.1186/s12912-020-00517-8.

Additional file 1. Delphi First Round Questionnaire

Additional file 2. Delphi Second Round Questionnaire

Additional file 3. Delphi Third round questionnaire

\section{Abbreviations}

COPD: Chronic obstructive pulmonary disease; OH: Oral health; NPO: Nil per os = nothing by mouth

\section{Acknowledgements}

This project was funded by the National Agency for Strategic Research in Medical Education, Tehran, Iran. Grant No.960082. The authors express their gratitude to the National Agency for Strategic Research in Medical Education and Shahid Sadoughi University of Medical Sciences and professors participating in the study from the School of Nursing and Midwifery and School of Dentistry.

\section{Authors' contributions}

SHT \& KHN \& FA1 conceptualized and designed the study. FO \& HA \& FA2 collected the data. KHN \& FRM analyzed the data. All authors have met criteria for authorship and had a role in preparing the manuscript. Also all authors approved the final manuscript.

\section{Funding}

This study was supported by a grant from the National Center for Strategic Research in Medical Education (NASR) in Ministry of Health and Medical Education (960082) Tehran, Iran. The grant supported data collection process. The funders had no role in the design of the study and collection, and analysis, interpretation of data or preparation of the manuscript. The report of the study's findings is sent by the authors to funder at the end of the study.

\section{Availability of data and materials}

The datasets used and/or analyzed during the current study are available from the corresponding author on reasonable request.

\section{Ethics approval and consent to participate}

This study was approved by the Committee of Ethics in Human Research at Shahid Sadoughi University of Medical Sciences in Yazd $(\$ 44529,2017)$. Before the first round started, informed written consent forms were obtained from all participants.

\section{Consent for publication}

Not Applicable.

Competing interests

The authors declare that they have no competing interests.

\section{Author details}

${ }^{1}$ Department of Oral and Maxillofacial Pathology, Social Determinants of Oral Health Research Center, School of Dentistry, Shahid Sadoughi University of Medical Sciences, Yazd, Iran. ${ }^{2}$ Department of Oral and Maxillofacial Medicine, School of Dentistry, Shahid Sadoughi University of Medical Sciences, Yazd, Iran. ${ }^{3}$ Endodontics Department, School of Dentistry, Shahid Sadoughi University of Medical Sciences, Yazd, Iran. ${ }^{4}$ Department of Periodontics, School of Dentistry, Shahid Sadoughi University of Medical Sciences, Yazd, Iran. ${ }^{5}$ Medical Education, School of Dentistry, Shahid Sadoughi University of Medical Sciences, Yazd, Iran. 'Department of Nursing, School of Nursing, Mother and Newborn Health Research Center, Nursing and midwifery Research Center, Shahid Sadoughi University of Medical Sciences, Yazd, Iran.

Received: 24 June 2020 Accepted: 7 December 2020

Published online: 11 December 2020

\section{References}

1. Yao K, Yao Y, Shen X, Lu C, Guo Q. Assessment of the oral health behavior, knowledge and status among dental and medical undergraduate students: a cross-sectional study. BMC Oral Health. 2019;19(1):26.

2. Dali M, Laleet R. A study on oral health knowledge, attitude, and practice among population of Siswani Jahada VDC in Biratnagar City, Nepal-a questionnaire survey. Asian Pac J Health Sci. 2014:12:51-6.

3. Musa MFC, Hassan YR, Rahman F, Jeenia FT. Provision of health and dental Care in two Middle Income Asian Countries. J Biotechnol Strateg Health Res. 2018;2(3):182-8.

4. Lages VA, Dutra TTB, Lima ANDAN, Mendes RF, Prado JÚnior RR. The impact of hospitalization on periodontal health status: an observational study. Rev Gaucha Odontol. 2017;65(3):216-22.

5. Hoeksema AR, Peters LL, Raghoebar GM, Meijer HJA, Vissink A, Visser A. Oral health status and need for oral care of care-dependent indwelling elderly: from admission to death. Clin Oral Investig. 2017;21(7):2189-96.

6. da Cruz MK, Morais TM, Trevisani DM. Clinical assessment of the oral cavity of patients hospitalized in an intensive care unit of an emergency hospital. Rev Bras Ter Intensiva. 2014;26(4):379-83.

7. Terezakis E, Needleman I, Kumar N, Moles D, Agudo E. The impact of hospitalization on oral health: a systematic review. J Clin Periodontol. 2011; 38(7):628-36.

8. Shiraishi A, Yoshimura Y, Wakabayashi H, Tsuji Y. Poor oral status is associated with rehabilitation outcome in older people. Geriatr Gerontol Int. 2017:17(4):598-604

9. Carrilho Neto A, De Paula RS, Sant'Ana A, Passanezi E. Oral health status among hospitalized patients. Int J Dent Hyg. 2011;9(1):21-9.

10. Musa TH, Li W, Li X, Wang WX, Soro WL, Gao R, Song Y, He Y, Hong L, Musa $\mathrm{HH}$, et al. Prevalence of dental caries profile in children and adolescents in rural Jiangsu Province. Arch Dis Child. 2018;103(12):1184-5. 
11. Nazir MA. Prevalence of periodontal disease, its association with systemic diseases and prevention. Int J Health Sci. 2017;11(2):72.

12. Walia M, Saini N. Relationship between periodontal diseases and preterm birth: recent epidemiological and biological data. Int J Appl Basic Med Res. 2015;5(1):2.

13. Mahmoud SR. Oral health knowledge, attitude and behavior of nursing school students in Assiut city. AAMJ. 2013;11(3):27-50.

14. Hahn JE, Fitzgerald L, Markham YK, Glassman P, Guenther N. Infusing oral health care into nursing curriculum: addressing preventive health in aging and disability. Nurs Res Pract. 2012;2012:157874.

15. Taheri N, Kamangar S, Mousavy SZ. Knowledge, attitude and practice toward Oral health: the case of Abadan nursing school students in 2011. Jundishapur J Health Sci. 2013;5(2):107-15.

16. Reigle JA, Holm K. Knowledge of oral health of nursing staff caring for disadvantaged older people. Journal of Nursing Education and Practice. 2016;6(1):31-8.

17. Walker K, Jackson R, Edwards PC, Vadaparampil ST. HPV and Oral Cancer: the need to integrate Oral health practices into nursing education. Clin J Oncol Nurs. 2018;22(6):166-73.

18. Safaa Rashad M. Oral health knowledge, attitude and behavior of nursing school students in Assiut city. Al-Azhar Assiut Med J. 2013;11(3):28-50.

19. Muttineni N, Bolla SC, Naheeda S, Shaik RB, Reddy SS, Gantha NS. Oral health awareness among the final year undergraduate nursing students in Khammam district, Telangana. J Health Res Rev. 2014;1 (3):70.

20. Kent KA, Clark CA. Open wide and say A-ha: adding Oral health content to the nurse practitioner curriculum. Nurs Educ Perspect. 2018;39(4):253-4.

21. Philip P, Villarosa A, Gopinath A, Elizabeth C, Norman G, George A. Oral health knowledge, attitude and practices among nurses in a tertiary care hospital in Bangalore, India: a cross-sectional survey. Contemp Nurse. 2019;55(2-3):261-74.

22. Jablonski RA. Oral health and hygiene content in nursing fundamentals textbooks. Nurs Res Pract. 2012;2012:372617.

23. Gambetta-Tessini K, Mariño R, Ghanim A, Calache H, Manton DJ. Knowledge, experience and perceptions regarding molar-incisor Hypomineralisation $(\mathrm{MIH})$ amongst Australian and Chilean public oral health care practitioners. BMC Oral Health. 2016;16(1):75.

24. McPherson S, Reese C, Wendler MC. Methodology update: Delphi studies. Nurs Res. 2018;67(5):404-10.

25. Ahmadi F, Nasiriani K, Abazari P. Delphi technique: a research tool. Iran J Med Educ. 2008;8(1):175-85.

26. Diamond IR, Grant RC, Feldman BM, Pencharz PB, Ling SC, Moore AM, Wales PW. Defining consensus: a systematic review recommends methodologic criteria for reporting of Delphi studies. J Clin Epidemiol. 2014;67(4):401-9.

27. Dehghani K, Nasiriani K, Salimi T. Requirements for nurse supervisor training: a qualitative content analysis. Iran J Nurs Midwifery Res. 2016;21(1):63-70.

28. Elo S, Kääriäinen M, Kanste O, Pölkki T, Utriainen K, Kyngäs H. Qualitative content analysis: a focus on trustworthiness. SAGE Open. 2014;4(1):1-10.

29. Shokouhi M, Khorasani-Zavareh D, Rezapur-Shahkolai F, Khankeh H, Nasiriani K. Safety concept of fire related injuries in inhabitants of residential buildings in Iran: a qualitative study. Injury. 2020;51(8):1817-22.

30. Dagnew ZA, Abraham IA, Beraki GG, Mittler S, Achila OO, Tesfamariam EH. Do nurses have barriers to quality oral care practice at a generalized hospital care in Asmara, Eritrea? A cross-sectional study. BMC Oral Health. 2020;20(1):149.

31. Bhagat $\mathrm{V}$, Hoang $\mathrm{H}$, Crocombe LA, Goldberg LR. Incorporating oral health care education in undergraduate nursing curricula - a systematic review. BMC Nurs. 2020;19(1):66.

32. Haresaku S, Aoki H, Makino M, Monji M, Kansui A, Kubota K, Naito T. Practices, attitudes, and confidence of nurses in the performance of Oral health checkups for elderly patients in a Japanese hospital. Oral Health Prev Dent. 2018;16(6):517-24

33. Lee YJ, Noh HJ, Han SY, Jeon HS, Chung WG, Mun SJ. Oral health care provided by nurses for hospitalized patients in Korea. Int J Dent Hyg. 2019:17(4):336-42

34. Rwakatema DS, Ananduni KN, Katiti WW, Msuya M, Chugulu J, Kapanda G. Oral health in nursing students at Kilimanjaro Christian medical Centre teaching hospital in Moshi, Tanzania. BMC Oral Health. 2015;15:23.

35. Khanbodaghi A, Natto ZS, Forero M, Loo CY. Effectiveness of interprofessional oral health program for pediatric nurse practitioner students at Northeastern University, United States. BMC Oral Health. 2019;19(1):170

\section{Publisher's Note}

Springer Nature remains neutral with regard to jurisdictional claims in published maps and institutional affiliations.

\section{Ready to submit your research? Choose BMC and benefit from:}

- fast, convenient online submission

- thorough peer review by experienced researchers in your field

- rapid publication on acceptance

- support for research data, including large and complex data types

- gold Open Access which fosters wider collaboration and increased citations

- maximum visibility for your research: over $100 \mathrm{M}$ website views per year

At BMC, research is always in progress.

Learn more biomedcentral.com/submissions 